Revista de

Contabilidade e

Organizações
DOI: http://dx.doi.org/10.11606/rco.v8i22.55615
Journal of

Accounting and

Organizations

\title{
Relação entre competências empreendedoras e desempenho: um estudo em em- presas prestadoras de serviços contábeis
}

\author{
Suzete Antonieta Lizotea; Miguel Angel Verdinelli ${ }^{\mathrm{b}}$ \\ aniversidade do Vale do Itajai \\ ${ }^{b}$ Universidad de Alicante
}

\section{Informações do Artigo}

\section{Histórico do Artigo}

Recebido: 15 de maio de 2013

Aceito: 16 de setembro de 2014

Palavras chave

Competências

Desempenho

Contabilidade.

\begin{abstract}
Resumo
O objetivo deste artigo é explicar a relação entre o desempenho de 103 empresas prestadoras e serviços contábeis do Estado de Santa Catarina e as competências empreendedoras dos seus proprietários, conforme a abordagem de Lenzi (2008). O referencial teórico apresenta os temas essenciais que se associam à problemática do estudo, quais sejam: competências empreendedoras e desempenho organizacional. Para a análise destas relações a abordagem neste artigo, de natureza aplicada, foi majoritariamente quantitativa. As características do estudo o posicionam como de objetivo descritivo e os procedimentos técnicos adotados foram a pesquisa bibliográfica, estudo multicasos e a survey com questionário. Para o processamento dos dados foram aplicadas técnicas estatísticas descritivas e inferenciais. Usaramse métodos multivariados (análise de correspondências e análise de agrupamentos) e univariados (teste de Mann-Whitney, teste de Kruskal-Wallis e correlação de Pearson), empregando os softwares SPSS e STATISTICA. As empresas foram segmentadas em quatro grupos em função das competências que os proprietários manifestavam e com base nesses dados se comprovaram diferenças no desempenho médio. Também se encontraram que segundo o grupo em que as organizações se encontravam as competências empreendedoras que se relacionam com o desempenho variam. Ao considerar os quatro grupos, das cinco competências que compõem o conjunto realização só duas apresentam relações significativas com o desempenho: busca de oportunidades e iniciativas; exigência de qualidade e eficiência. Para o conjunto planejamento as três que o constituem: busca de informação, estabelecimento de metas e planejamento e monitoramento sistemáticos e só uma das duas para o conjunto poder: independência e autoconfiança.
\end{abstract}

Copyright (C) 2014 FEA-RP/USP. Todos os direitos reservados

\section{INTRODUÇÃO}

A estratégia empresarial apresenta inúmeros desafios como, por exemplo, as frequentes mudanças que ocorrem no ambiente de negócio. Contudo, para enfrentá-los e ainda prosperar, torna-se necessário que os gestores e proprietários contem com atributos que os destaquem frente à concorrência.

Se o ambiente for considerado com base numa visão cognitiva, por oposição à corrente que sustenta a sua existência real, a competência de administradores

Autor Correspondente: Tel + 5547 3341-7779

E-mail : lizote@univali.br (S. A. Lizote); maverdinelli@gmail.com (M. A. Verdinelli)

Universidade do Vale do Itajaí - Programa de Pós- Graduação em Administração, Centro de Educação Biguaçu - Rua João Coan, 400 - Centro - 88160000 - Biguacu - SC, Brasil e funcionários é fundamental. Eles precisam saber reconhecer, interpretar e implementar estratégias que por uma parte garanta a continuidade da empresa e por outra forneçam vantagens competitivas, pois sendo as mudanças comum a todas organizações aquelas que saibam alterar sua base de recursos e capacidades para se ajustar ao novo estado serão as que se sobressaiam.

A rápida adequação organizacional é interpretada como uma capacidade ou orientação empreendedora, a que pressupõe proatividade, inovatividade e assunção de riscos de parte dos empregados e gestores. Diante destas colocações, constata-se que o empreendedor, é alguém capaz de desenvolver uma visão sobre negócios, persuadir pessoas e identificar uma oportunidade de mercado onde os outros nada ou pouco enxergam. Além disso, eles têm energia, esperança e paixão pelo que fazem (DORNELAS, 2003). Consequentemente, a associação da orientação empreendedora com o desempenho tem sido motivo de intensa investigação ao 
nível internacional e no Brasil se vem acompanhando tal tendência.

São empreendedores aqueles que criam um negócio novo, diferente, mudando ou transformando valores. $\mathrm{O}$ espírito empreendedor é uma característica distinta de uma instituição ou de um indivíduo. McClelland (1971) define empreendedor como o criador de uma nova empresa ou o administrador que tenta melhorar uma unidade organizacional pela

introdução de mudanças produtivas. Para Schumpeter (1978), é quem faz novas combinações de elementos, inventando novos produtos e processos, identificando novos mercados de exportação ou fontes de suprimento, criando novos tipos de organização, na busca do desenvolvimento regional.

$\mathrm{Na}$ visão de Kent, Sexton e Vesper (1982), empreendedor de sucesso é todo indivíduo que, estando na qualidade de principal tomador das decisões envolvidas, conseguiu formar um novo negócio ou desenvolver negócios já existentes, elevando substancialmente seu valor patrimonial, várias vezes acima da média esperada das empresas congêneres do mesmo contexto sócio-político-econômico, tendo granjeado com isso alto prestígio perante a maioria das pessoas que conhecem essa empresa ou têm relacionamento com ela. Smith (1985) identifica o empreendedor como um proprietário capitalista, um administrador que se situa entre o trabalhador e o consumidor, pois naquela década de 1980, ele era considerado como alguém que visava apenas o fazer dinheiro. Na linha de pensamento daquele autor, Drucker (1987) ressalta que o ele sempre está buscando mudança, reage a ela, e a explora como sendo uma oportunidade.

O empreendedor, conforme Cunningham e Lischeron (1991), possui alto nível de energia e alto grau de perseverança e imaginação, que combinados com a disposição para correr riscos moderados, capacitam-nos a transformar o que, frequentemente, começa como uma ideia ou visão simples e mal definida em algo concreto. Corroboram Filion (1999); Gimenez e Inácio Júnior (2002) ao considerarem que os mesmos têm em comum o compromisso com a prática sistemática da inovação, e é o meio pelo qual ele cria novos recursos produtores de riqueza ou os investe com maior potencial para sua criação.

Hisrich, Peter e Shepherd (2009) seguem a mesma linha, observando que empreendedor é aquele que combina recursos, materiais e outros ativos para tornar seu valor maior do que antes; também é aquele que introduz mudanças, inovações e uma nova ordem.

Entende-se, desta forma, que atualmente as entidades devem adotar uma gestão empreendedora para prosperar e sobreviver no contexto de grandes mudanças. É preciso também promover a liberdade de ação em todos os níveis da empresa de modo participativo, o que deve ser a regra de conduta e orientação gerencial no processo de tomada de decisões.

Em resumo pode se dizer que os problemas complexos que surgem nos ambientes de negócios exigem que as equipes de trabalho apresentem características apropriadas para enfrenta-los e, desta forma, a ênfase direcionam-se às pessoas, seus comportamentos e modos de trabalho. As organizações precisam contar com trabalhadores comprometidos, capazes de perceber e perseguir oportunidades, ou seja, que tenham ou estejam dispostos a desenvolver suas competências. Os contadores ocupam uma posição estratégica para as empresas, no estímulo ao desenvolvimento empreendedor e consequente desenvolvimento econômico do país. Suas atividades estão relacionadas com planejamento, acompanhamento da execução e controles financeiros e operacionais, existentes em diversas características empreendedoras.

Neste trabalho pretende-se analisar o relacionamento entre as competências empreendedoras dos proprietários de empresas prestadoras de serviços contábeis em relação ao desempenho por eles percebido, procurando dar resposta ao seguinte questionamento:

A presença de competências empreendedoras dos donos de empresas prestadoras de serviços contábeis se relaciona positivamente com o desempenho?

Estudos desta natureza podem contribuir significativamente para as práticas gerenciais buscando direcionar as ações que estimulem a presença do empreendedor corporativo como agente de inovação, assim como, os resultados alcançados e articulação com o referencial teórico permitem planejar atitudes que contribuam para a área do empreendedorismo.

O artigo está estruturado em 5 seções, iniciando com esta introdução; a seção 2 apresenta a síntese da discussão teórica sobre competências empreendedoras e desempenho; a abordagem metodológica é apresentada na seção seguinte; as análises e discussão dos dados estão evidenciadas na seção 4. Por último, são feitas as considerações finais da pesquisa e é disponibilizado o referencial bibliográfico.

\section{MARCO TEÓRICO}

\subsection{Competências empreendedoras}

O contexto da nova economia evidencia um cenário transformador, devendo os empreendimentos adaptar-se com rapidez para a continuidade do seu desenvolvimento, trabalhando, desta forma, na busca continuada de competências, voltadas a satisfação das necessidades internas e externas. Segundo Zarifian (2001), para ser identificada e compreendida, a competência do indivíduo precisa ser observada na ação. 
A maneira como o sujeito articula seus recursos para enfrentar situações de trabalho e de sua vida pessoal resulta na expressão da mesma. Neste sentido, competência segundo Nassif; Andreassi e Simões (2011, p. 38) "pode ser considerada como um último nível da característica de um indivíduo, abordando diferentes traços de personalidade, habilidades e conhecimentos, que partem das influências de experiências, treinamentos, educação, família e outras variáveis demográficas".

Nesta ótica, o indivíduo tem que estar preparado para enfrentar o mundo informacional e globalizado, ato este que exige tanto o saber fazer, como o saber ser. Estes imperativos são essenciais para a sobrevivência, contextualizada no aprender a aprender e podem ser traduzidos na prática de geração do crescimento organizacional através de mecanismos recursivos de formação de competências.

Para Mello, Leão e Paiva Jr. (2006), a competência, consiste num corpo de conhecimento, área ou habilidade, qualidades pessoais ou características, atitudes ou visões, motivações ou direcionamentos, que podem, de diferentes formas, contribuírem para o pensamento ou ação efetiva do negócio.

Existem competências associadas às posturas empreendedoras que auxiliam na compreensão de atributos geradores de respostas de valor na interação com grupos internos e externos da organização. Segundo Mamede e Moreira (2005), elas se vinculam ao senso de identificação de oportunidades, à capacidade de relacionamento em rede, às habilidades conceituais, à capacidade de gestão, à facilidade de leitura, ao posicionamento em cenários conjunturais e ao comprometimento com interesses individuais e da organização.

Para Snell e Lau (1994), competências empreendedoras consistem na junção de competências e ações empreendedoras, por tratarem-se de um corpo de conhecimentos, motivações ou direcionamentos, atitudes ou visões, que podem de diferentes formas, contribuir para o pensamento ou ação efetiva do negócio.

Man e Lau (2000), por sua vez, as consideram como tipo de características superiores que faz com que o indivíduo se destaque, por diferentes traços de personalidade, habilidades e conhecimentos, que se manifestam na atitude. Complementa Le Boterf (2003), que estes traços são influenciados pela sua educação tradicional e familiar, assim como pela sua experiência.

As competências empreendedoras para Antonello (2005) são um conjunto de habilidades e atitudes que viabilizam um indivíduo imprimir sua visão, estratégias e ações na criação de valor tangíveis e intangíveis para sociedade. Nesta mesma linha de pensamento Lenzi (2008) e Lenzi et al. (2011) argumentam que são originadas por resultados constantes dos empreendedores corporativos. Lenzi (2008, p. 46) afirma que “Assim como uma pessoa pode lapidar suas próprias competências, um empreendedor pode construir e adequar suas individualidades a fim de criar uma competência empreendedora".

Mitchelmore e Rowley (2010) por meio de uma revisão teórica organizaram um quadro com quatro categorias de análise das competências empreendedoras, sendo elas: i) negócios e competências gerenciais (foco no desenvolvimento de recursos, aspectos operacionais e estratégicos); ii) competências e relações humanas (foco na cultura, liderança e pessoas): iii) competências conceituais e de relacionamento (foco na comunicação, relacionamento com stakeholders e tomada de decisão); e, iv) competências empreendedoras (foco na inovação).

Schmitz (2012, p. 73), com base em Rosa e Lapoli (2010), adotou como conceito de competência empreendedora "comportamento, habilidade e atitude de um individuo que, diante de situações críticas de trabalho, motiva-se à busca de soluções, que irão resultar em benefício institucional e satisfação da necessidade de realização do indivíduo".

Esses autores apontam para uma relação entre determinados traços ou características das competências e o sucesso na condução de negócios. Assim, tal relação nos remete ao estudo dos modelos de competências.

David McClelland, em 1973, propôs um modelo de competências quando fez algumas críticas aos testes tradicionais de aptidão e conhecimento. Afirmava que eles não previam o desempenho no trabalho ou o sucesso na vida e foram tendenciosos contra minorias, mulheres e pessoas de nível sócio econômico mais baixo (SPENCER e SPENCER, 1993).

Em 1983, a Agência dos Estados Unidos para o Desenvolvimento Internacional (USAID) financiou uma pesquisa em três países subdesenvolvidos na América Latina (Equador), África (Malawi) e Ásia (Índia) para identificar características empreendedoras pessoais. Ou seja, competências capazes de prever a criação e sucesso de negócios em diferentes culturas. O objetivo do estudo era multiplicar e estender a aplicação dos conhecimentos sobre motivação usando a metodologia de mensuração de competências desenvolvida por Lyle Spencer e David McClelland.

Alguns autores tem se preocupado, dentro do tema competências empreendedoras, em criar tipologias que possibilitem a identificação por parte dos pesquisadores das competências necessárias ao desenvolvimento de suas atividades.

Dentre eles, destaca-se o trabalho de Lenzi (2008), o qual aborda o trabalho desenvolvido por Cooley (1990, 1991). Neste estudo foram destacadas dez características de comportamento empreendedor, também chamadas de competências empreendedoras, agrupadas em 3 categorias conforme demonstra-se no Quadro 1. 


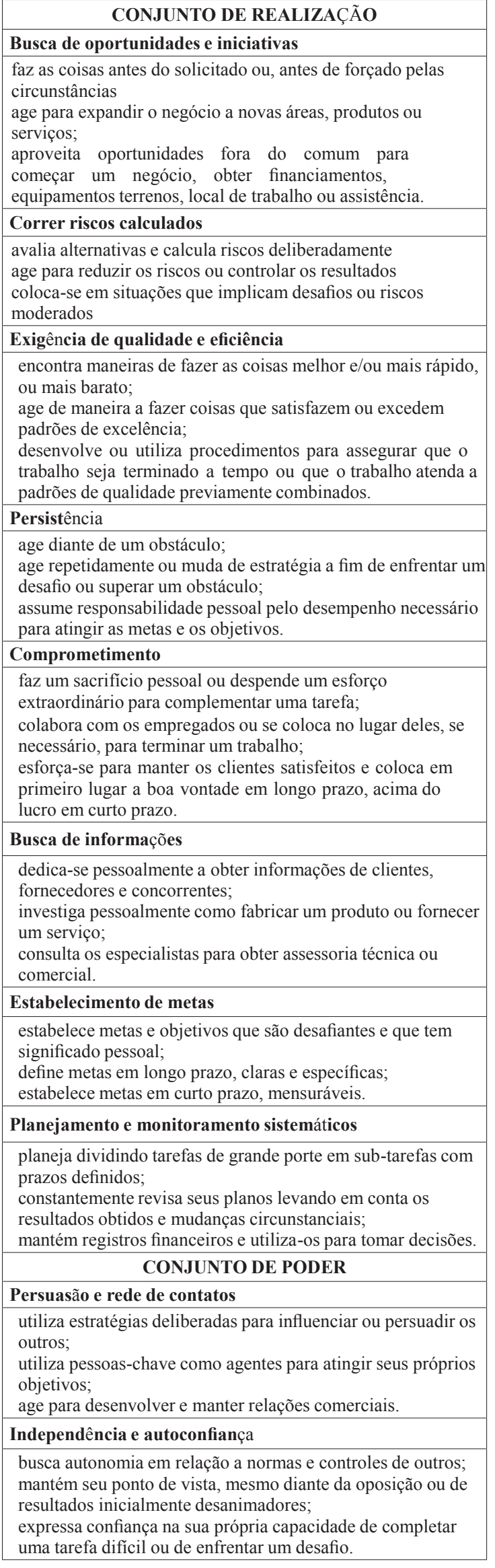

Quadro 1. Competências empreendedoras

Fonte: Lenzi (2008)
Este modelo atualmente é utilizado pelo Programa das Nações Unidas para o Desenvolvimento (PNUD), e também pelo Serviço de Apoio a Pequena Empresa (SEBRAE), para programas de capacitação dos empreendedores, como o Programa para Empresários e Futuros Empreendedores (EMPRETEC).

Morales (2004) utilizou-o procurando medir o grau de relação entre as competências empreendedoras e os tipos psicológicos Junguianos. A pesquisa foi realizada com oitenta e dois empreendedores no estado de Santa Catarina. Nessa amostra, as duas competências empreendedoras dominantes foram: busca de informações e persuasão e rede de contatos. Também se constatou para o grupo pesquisado que houve baixa correlação entre os tipos psicológicos e as competências.

Lenzi (2008) desenvolveu sua tese com ênfase na identificação e associação de tipos psicológicos de Jung e competências empreendedoras reconhecidas nos indivíduos considerados empreendedores. A amostra foi de cento e vinte e seis pesquisados em onze empresas de grande porte localizadas no estado de Santa Catarina. Neste estudo, as competências empreendedoras que mais se destacaram foram: correr riscos calculados; persistência; comprometimento; busca de informações e persuasão e rede de contatos. Também foi possível confirmar um alto grau de significância na associação dos tipos psicológicos predominantes às competências empreendedoras identificadas por colegas de trabalho.

Rosa e Lapoli (2010, p. 24), ao tratar dos talentos empreendedores no Estado de Santa Catarina afirmam que em determinados contextos algumas competências fazem mais sentidos às ações individuais que outras. Argumentam também que "[...] para atingir o alto desempenho em determinado mercado algumas competências podem ser mais importantes, mas de modo geral todas elas devem estar presentes para que uma ação empreendedora gere os resultados esperados [...]"

Schmitz (2012) buscou identificar as competências empreendedoras requeridas pelos gestores de Instituições de Ensino Superior. A pesquisa foi realizada em três universidades do Brasil e uma de Portugal. A amostra constitui-se de 134 entrevistados. Os resultados dapesquisa identificaram a independência e a autoconfiança como as competências empreendedoras mais apontadas.

As dez competências empreendedoras e suas 30 definições operacionais de comportamentos serão utilizadas neste trabalho para estudar a relação entre competências dos proprietários de empresas prestadoras de serviços contábeis e seu desempenho. Considera-se que as competências individuais possibilitem aos gestores reconhecer e atuar perante as oportunidades de inovação assumindo os riscos inerentes.

\subsection{Desempenho organizacional}

A avaliação de desempenho serve para controlar 
uma estratégia estabelecida pela

empresa, confrontando seu resultado com os objetivos estabelecidos. Nesta ótica, Simons (2000) coloca que a ela é considerada uma das ferramentas de controle para as organizações. Para Rocha (2002), sua finalidade é identificar se as atividades estão ocorrendo de forma correta na empresa. Para Olson, Slater e Hult (2005) o desempenho das entidades é determinado pela forma eficaz e eficiente de implementar suas estratégias de negócios, sobretudo como adotam comportamentos de orientação ao cliente, como analisam seus concorrentes, como percebem e adotam as inovações pertinentes e como lidam com os custos de gestão.

O desempenho pode ser mensurado através de duas perspectivas: primeiramente como conceito subjetivo, o qual está relacionado ao desempenho das organizações segundo a sua própria expectativa (PELHAM; WILSON, 1996) ou relativamente à competição. A segunda, analisálo pelo método objetivo, baseado em medidas absolutas de desempenho (CHAKRAVARTHY, 1996).

Os motivos pelos quais são escolhidas as medidas subjetivas comentam Wang e Ang (2004), ocorrem porque parcela significativa de pequenas empresas não possuem ou dispõem de poucas informações objetivas e se torna quase que impossível conferi-las com precisão.

Em se tratando a respeito de medidas objetivas a pesquisa de Perin e Sampaio (1999) apresentaram um estudo que demonstrou a validade do uso de indicadores subjetivos (de percepção) e objetivos do tipo self-report, como alternativa viável para o caso de inexistência de dados secundários confiáveis. No estudo de Gulini e Rossetto (2005), os autores investigaram 79 empresas do setor de provedores de internet no estado de Santa Catarina, analisaram a relação entre a percepção do ambiente organizacional, comportamento estratégico e desempenho, usando medidas subjetivas para avaliar o desempenho empresarial (Taxa de crescimento de vendas, Taxa de retenção dos clientes, lucratividade e desempenho geral).

Andretti (2008) analisou o relacionamento entre comportamento estratégico, ambiente organizacional e desempenho empresarial na percepção de 22 gestores de hotéis da cidade de Macaé, no estado do Rio de Janeiro. Utilizou medidas subjetivas para avaliar o desempenho, sendo cinco variáveis (Taxa Média de Ocupação, Incremento na Participação do Mercado, Acréscimo do Número de clientes, Repetição do Número de clientes e Acréscimo da Receita Total).

Marins e Zawislak (2010) sugeriram um conjunto de novos indicadores de inovação, usando medidas subjetivas (P\&D, Criatividade, Capacidade de realização, Externalização, Interatividade, Recursos físicos tangíveis, Aplicações tecnológicas, Lucro operacional inovativo e Valor agregado) e medidas objetivas de indicadores tradicionais (investimento em pesquisa e desenvolvimento (percentual do orçamento total da firma), número de doutores, número de patentes requeridas e número de patentes concedidas para avaliar o desempenho.

Para Marshall e Wray (1999) é mediante a análise do desempenho que as organizações podem medir a sua capacidade de sobrevivência e continuidade face às exigências do ambiente interno e externo, em que estejam inseridas. Entretanto, melhorias de desempenho exigem mudanças também nos sistemas de mediação e gestão utilizados pelas empresas, pois é impossível atingir a excelência empresarial controlando apenas as medidas financeiras do passado, visto que os gestores necessitam de indicadores sobre vários aspectos do ambiente e do desempenho organizacional.

\section{MATERIAL E MÉTODOS}

Os dados para este estudo foram gerados em Santa Catarina com os proprietários de cento e três (103) empresas prestadoras de serviços contábeis que estão instaladas em Itajaí (52) e em seis cidades próximas: Blumenau (15), Bombinhas (3), Brusque (9), Itapema (18), Piçarras (3) e Porto Belo (2). Para tanto se fez uma survey, usando como técnica de coleta o questionário.

O mesmo continha um primeiro bloco referido, conforme proposta em Lenzi (2008), às competências empreendedoras do conjunto de realização, incluindo busca de oportunidades e iniciativas (BOI), correr riscos calculados (CRC), exigência de qualidade e eficiência (EQE), persistência (PER), e comprometimento (COM); as do conjunto de planejamento, contemplando busca de informação (BDI), estabelecimento de metas (EDM), e planejamento e monitoramento sistemáticos (PMS); $\mathrm{e}$, as do conjunto de poder, que são relativas à persuasão e rede de contatos (PRC) e à independência e autoconfiança (IAC). Para cada uma das competências o proprietário do escritório contábil tinha três questões que devia responder numa escala intervalar de cinco pontos. Posteriormente, os três valores se somaram e alcançando um valor igual ou superior a doze (12), essa competência se considerava que estava manifesta.

Num segundo bloco, de acordo com a proposição de Gupta e Govindarajan (1984), levantaram-se dados atinentes ao desempenho, medido através de cinco descritores: lucratividade (L), crescimento das vendas $(\mathrm{CV})$, retenção de clientes (RC), faturamento mensal (FM) e desempenho geral (DG). Esses itens foram avaliados pela satisfação que eles proporcionam ponderada pela importância relativa que o respondente dá ao mesmo. Ou seja, os proprietários atribuíam um valor percentual à importância do indicador, sendo soma dos cinco igual a cem (100\%), e logo respondiam numa escala de cinco pontos a satisfação que cada um deles proporcionava. Com esses dados foi possível compor uma nova medida do desempenho contemplando ambos os aspectos. Também foi registrada a cidade onde a empresa funcionava e o sexo do proprietário.

Dos cento e três questionários respondidos foi eliminado um, pois nenhuma das competências atingiu o valor usado como limite para considerar que ela existia. A empresa está localizada na cidade de Brusque, de propriedade de uma mulher. Não houve dados faltantes 
em nenhum dos instrumentos recebidos.

Para o processamento dos dados foram aplicadas técnicas estatísticas descritivas e inferenciais. Usaramse métodos multivariados (análise de correspondências e análise de agrupamentos) e univariados (teste de Mann-Whitney, teste de Kruskal-Wallis e correlação de Pearson), empregando os softwares SPSS e STATISTICA.

A análise de correspondências é uma técnica fatorial multivariada que foi usada de modo exploratório com as competências empreendedoras. Para tanto se gerou uma matriz disjuntiva completa onde as empresas se assignava o valor 1 se a soma dos três itens da competência considerada alcança como mínimo o valor de 12 , caso contrário era 0 o valor atribuído, indicando que ela não se manifestava. Desenvolvida a análise usaram-se as coordenadas das quatro primeiras dimensões para diferenciar as empresas prestadoras de serviços contábeis através da análise de agrupamentos. Para usar essa técnica de maneira hierárquica escolheu-se o método de junção de Ward, que se baseia em minimizar a inércia dentro do grupo e maximizá-la entre os mesmos. Como medida de parecença escolheu-se a distância euclidiana. Definiu-se trabalhar com quatro grupos. Para tanto se usou o dendrograma gerado e a sequência de junção como médio apropriado para embasar a decisão.
A pertença das empresas aos grupos assim criados possibilitou operacionalizar as análises de variância. Entretanto, havendo falta de normalidade nos dados de desempenho teve que ser utilizado o teste não paramétrico de Kruskal-Wallis. Existindo diferenças na comparação simultânea se deu sequência para as comparações pareadas com o teste de Dunn.

\section{RESULTADOS}

Das cento e empresas prestadoras de serviços contábeis que se consideram neste trabalho trinta e quatro são propriedade de mulheres. Isto representa que para a amostra toda há uma relação de quase duas empresas cujo dono é um homem para um de propriedade feminina (2:1). Contudo, na cidade de Itajaí, onde se concentra mais da metade dos casos (52), a relação cai a $1,6: 1$.

Inicialmente para cada competência somaram-se os valores assinalados pelos respondentes aos três itens que cada uma dela tinha como indicadores. Obtidos esses somatórios procedeu-se ao calculo das correlações de Pearson entre as dez competências. Os resultados se exibem na Tabela 1.

Tabela 1. Matriz de correlações entre as competências empreendedoras.

\begin{tabular}{|c|c|c|c|c|c|c|c|c|c|c|}
\hline & $\mathrm{BOI}$ & CRC & EQE & PER & COM & BDI & EDM & PMS & PRC & $\mathrm{LAC}$ \\
\hline BOI & 1 & \multirow{3}{*}{1} & \multirow{5}{*}{1} & & & & & & & \\
\hline \multirow{2}{*}{ CRC } & 0,2151 & & & & & & & & & \\
\hline & $p=0,030$ & & & & & & & & & \\
\hline \multirow{2}{*}{ EQE } & 0,5567 & 0,1309 & & & & & & & & \\
\hline & $p=0,000$ & $p=0,190$ & & & & & & & & \\
\hline \multirow{2}{*}{ PER } & 0,1110 & 0,4758 & 0,0717 & \multirow{2}{*}{1} & \multirow{4}{*}{1} & & & & & \\
\hline & $p=0,267$ & $p=0,000$ & $\mathrm{p}=0.474$ & & & & & & & \\
\hline \multirow{2}{*}{ COM } & 0,0876 & 0,1705 & 0,0899 & 0,3203 & & \multirow{4}{*}{1} & & & & \\
\hline & $p=0,381$ & $\mathrm{p}=0,087$ & $p=0.369$ & $p=0,001$ & & & & & & \\
\hline \multirow{2}{*}{ BDI } & 0.2901 & 0.5201 & 0.2448 & 0.5403 & 0.2233 & & & & & \\
\hline & $p=0,003$ & $p=0,000$ & $p=0,013$ & $\mathrm{p}=0,000$ & $\mathrm{p}=0,024$ & & & & & \\
\hline \multirow{2}{*}{ EDM } & 0,1910 & 0,1511 & 0,1631 & 0.1644 & 0.0637 & 0.2871 & \multirow{2}{*}{1} & \multirow{4}{*}{1} & & \\
\hline & $p=0,054$ & $p=0,130$ & $p=0,101$ & $p=0,099$ & $p=0,525$ & $p=0,003$ & & & & \\
\hline \multirow{2}{*}{ PMS } & 0.0593 & 0,1363 & $-0,0126$ & 0,3447 & 0,0834 & 0,1210 & 0,1228 & & & \\
\hline & $\mathrm{p}=0,372$ & $p=0,172$ & $p=0,900$ & $p=0,000$ & $\mathrm{p}=0,405$ & $p=0,226$ & $p=0,219$ & & & \\
\hline \multirow{2}{*}{ PRC } & 0,2351 & 0,1356 & 0.1455 & 0.1490 & $-0,0401$ & 0,1424 & 0,1838 & 0,4289 & \multirow{2}{*}{1} & \\
\hline & $p=0,017$ & $p=0,174$ & $\mathrm{p}=0,144$ & $p=0,135$ & $p=0,659$ & $\mathrm{p}=0,153$ & $p=0,064$ & $p=0,000$ & & \\
\hline \multirow{2}{*}{ LAC } & 0,3488 & 0,3429 & 0,2311 & 0,4691 & 0,1846 & 0,4472 & 0,3481 & 0,2123 & 0,1359 & \multirow{2}{*}{1} \\
\hline & $p=0,000$ & $p=0,000$ & $p=0.019$ & $p=0,000$ & $p=0,063$ & $\mathrm{p}=0,000$ & $p=0,000$ & $p=0.032$ & $p=0,173$ & \\
\hline
\end{tabular}

Legenda: BOI: busca de oportunidades e iniciativas; CRC: correr riscos calculados; EQE: exigência de qualidade e eficiência; PER: persistência; COM: comprometimento; BDI: busca de informação; EDM: estabelecimento de metas; PMS: planejamento e monitoramento sistemáticos; PRC: persuasão e rede de contatos; IAC: independência e autoconfiança.

Fonte: Dados da pesquisa (2013)

Aanálise desses resultados indica que as competências dos conjuntos de realizações, planejamento e poder não se apresentam relacionados entre si e diferenciados dos outros conjuntos. Por exemplo, BDI e IEA se relacionam de modo significativo com sete outras. Assim sendo, optou-se por gerar uma nova base de dados usando o valor igual o maior do que

12, na soma dos três itens mensuravam a competência, para considerar que o respondente demonstrava ter ela.
Com tal procedimento criou-se uma matriz disjuntiva completa, ou tabela lógica e a partir desses novos dados foi feita uma comparação do número médio de competências empreendedoras que se manifestam nas empresas cuja proprietária era mulher em contraste com aqueles onde o dono era homem. Teve que se empregar o teste não-paramétrico de Mann-Whitney, devido à falta de normalidade dos dados, e se verificou que não houve diferenças significativas $(\mathrm{p}=0,2575)$, mostrando que as competências empreendedoras não se relacionam 
com o gênero do proprietário.

Seguidamente a tabela lógica foi processada pela análise de correspondências que ao reter os quatro primeiros fatores recuperou $63,02 \%$ da variância. Para cada dimensão ou fator se registrou o valor de coordenada para cada empresa contábil compondo uma nova base de dados. Esta nova matriz possibilitou desenvolver uma análise de agrupamentos hierárquica aos efeitos de reconhecer grupos homogêneos. A Figura 1 exibe o dendrograma gerado ao usar o método de Ward para criar os grupos e a distância euclidiana como medida de parecença.

Figura 1. Dendrograma dos cento e dois escritórios de contabilidade.

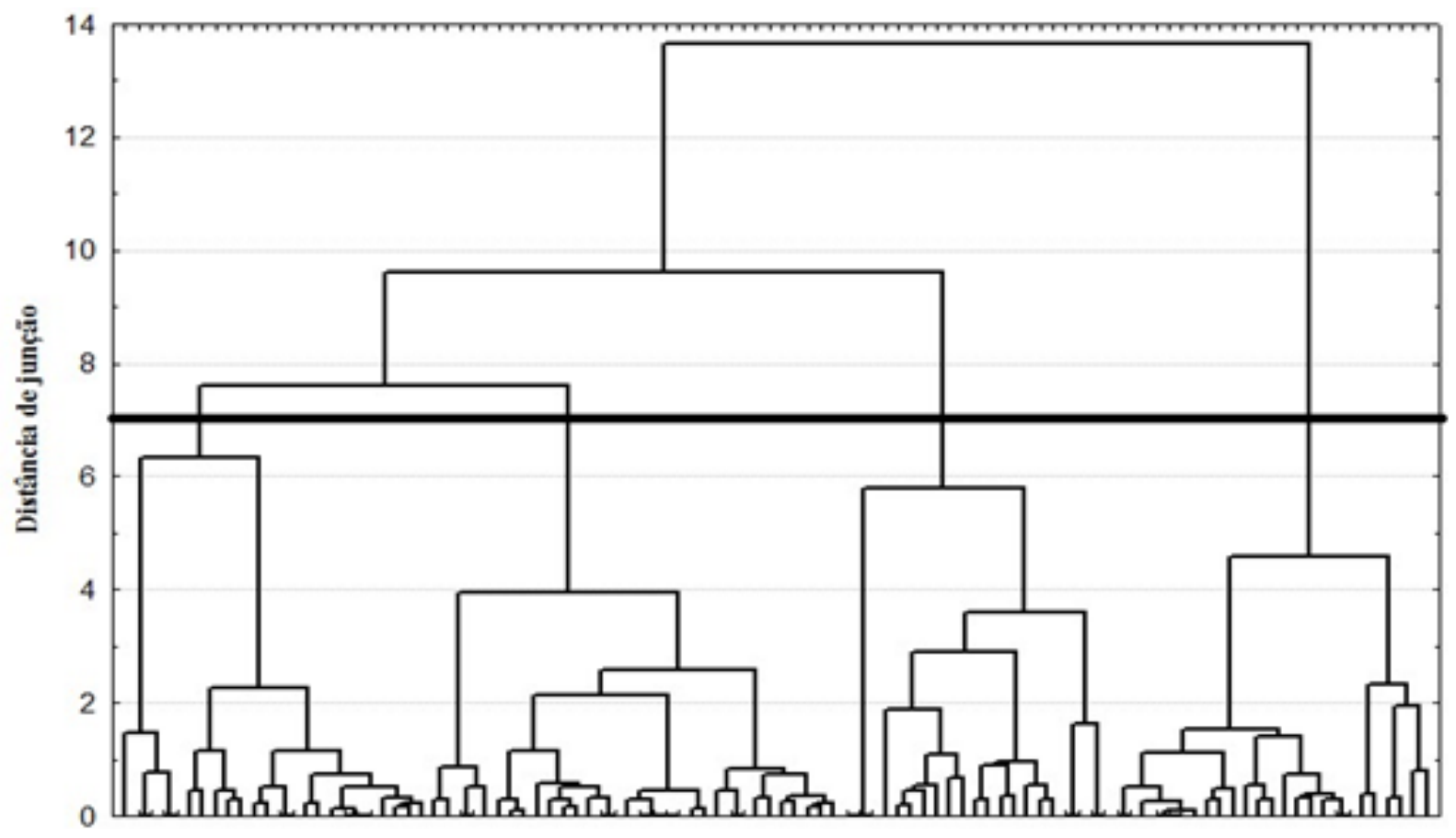

Legenda: A linha na distância de junção 7 permite reconhecer quatro grupos denominados de esquerda para direita como G1, G2, G3 e G4. Método de junção de Ward e medida de parecença distância euclidiana.

Fonte: Dados da pesquisa (2013)

O grupo G1, à esquerda na figura, contém 25 empresas, que em média manifestam 4,68 competências; em G2 há 32 e uma média de 6,31; G3 compreende 20 e média de 3,80; e, G4 inclui 25 escritórios que possuem a maior média de competências empreendedoras 7,12 . Face à falta de normalidade se testou a igualdade daqueles valores médios pelo teste não- paramétrico de KruskalWallis que mostrou diferencias significativas (Tabela 2).

Tabela . 2 Teste de Kruskal-Wallis

\begin{tabular}{c|c|c}
\hline Grupo & No casos $^{\text {coma dos }}$ & $\begin{array}{c}\text { Somas } \\
\text { postos }\end{array}$ \\
\hline G1 & 25 & 959,000 \\
\hline G2 & 32 & 1940,000 \\
\hline G3 & 20 & 579,000 \\
\hline G4 & 25 & 1775,000 \\
\hline
\end{tabular}

Legenda: para comparar o número de competências nos grupos. Valor calculado de $\mathrm{H}=30,96904, \mathrm{p}=0,0000$

Fonte: Dados da pesquisa (2013)

Desenvolvido o teste de Dunn para as comparações pareadas comprovou-se que o G1 tem diferenças com G2 e G4; por sua vez G2 se diferencia de G3; e, G3 é diferente de G4.

Contudo, ao avaliar quais as competências mais frequentes em cada grupo se constata que o comprometimento sempre está entre as competências que mais se destacam. Os valores registrados se mostram na Tabela 3.

Tabela 3. Frequências com que aparecem manifestas as competências empreendedoras em cada grupo.

\begin{tabular}{c|c|c|c|c|c|c|c|c|c|c}
\hline & BOI & CRC & EQE & PER & COM & BDI & EDM & PMS & PRC & IAC \\
\hline G1 & 0 & 16 & 1 & 17 & 21 & 10 & 7 & 21 & 21 & 3 \\
\hline G2 & 0 & 10 & 14 & 27 & 31 & 23 & 23 & 21 & 25 & 28 \\
\hline G3 & 0 & 9 & 13 & 14 & 18 & 7 & 0 & 5 & 7 & 3 \\
\hline G4 & 25 & 16 & 21 & 15 & 22 & 18 & 13 & 15 & 16 & 17 \\
\hline
\end{tabular}

Fonte: Dados da pesquisa (2013)

O que caracteriza aos diversos grupos são os baixos ou altos valores com que ocorrem certas competências. Assim o G1 mostra o menor valor para EQE, o G2 é quem exibe o maior valor de IAC, enquanto G3 mostra o menor valor de EDM e G4 é o único que reúne em todos os escritórios que compõem o grupo a competência BOI.

Considerando tais diferenças cabe analisar se o desempenho é percebido da mesma maneira por todos os grupos. Nesse sentido, primeiro se ponderou a satisfação com os indicadores empregados em função da importância a eles atribuídos pelos respondentes. Seguidamente, testou-se a normalidade e ao não 
apresentar tal condição se desenvolveu o teste de Kruskal-Wallis para cada um dos cinco indicadores empregados. A lucratividade, crescimento das vendas, retenção de clientes e faturamento mensal não mostraram diferenças significativas entre si, enquanto o desempenho geral sim.

A significância do resultado para o desempenho ponderado pela importância, isto é o valor-p, na comparação simultânea mostrou que as percepções eram diferentes (Tabela 4).

Tabela 4. Teste de Kruskal-Wallis

\begin{tabular}{c|c|c}
\hline Grupo & No casos & $\begin{array}{c}\text { Soma dos } \\
\text { postos }\end{array}$ \\
\hline G1 & 25 & 843,000 \\
\hline G2 & 32 & 1787,000 \\
\hline G3 & 20 & 1233,000 \\
\hline G4 & 25 & 1390,000 \\
\hline
\end{tabular}

Leganda: comparar o desempenho percebido nos grupos. Valor calculado de $\mathrm{H}=13,73334$, $\mathrm{p}=0,0033$.

Fonte: Dados da pesquisa (2013)

As comparações pareadas, ao realizar o teste de Dunn, mostraram que o G1 é sempre menor que os demais grupos. Estes, por sua parte, quando comparados em pares não apresentam diferenças entre si.

Em face de esses resultados buscou-se saber se o que influenciava era a importância que davam ao descritor do desempenho, se era a satisfação que ele proporcionava ou ambas as razões. Duas novas análises foram então efetuadas e só quando se testou a importância dada ao desempenho foi que houve significância na comparação simultânea $(\mathrm{p}=0,0000)$. As comparações em pares indicaram novamente que as empresas prestadoras de serviços contábeis inseridos no G1 foram os que deram menor importância. Sua média foi de 10,4\%, enquanto que as médias dos outros grupos foram: $13,13 \%$ para $\mathrm{G} 2,14 \%$ para $\mathrm{G} 3$ e $13,6 \%$ para $\mathrm{G} 4$, todas estatisticamente iguais entre si.

Finalmente, para avaliar quais competências tem relação com o desempenho se computaram as correlações entre os valores somativos dos três itens que se empregaram paracada uma delas com o desempenho ponderado pela importância dada ao indicador. Devese levar em conta que os valores relativos a cada empresa não superam necessariamente o valor limite de 12, utilizado para considerar uma competência como realmente presente. Os resultados, em tais condições, são apresentados na Tabela 5.

Tabela 5 - Correlações entre os valores

\begin{tabular}{c|c|c|c|c|c|c|c|c|c|c}
\multicolumn{2}{c}{ BOI } & CRC & EQE & PER & COM & BDI & EDM & PMS & PRC & IAC \\
\hline \multirow{2}{*}{ G1 } & 0,086362 & $-0,099241$ & 0,208310 & 0,121034 & 0,129440 & 0,445794 & 0,465511 & 0,033541 & $-0,088643$ & 0,369357 \\
\cline { 2 - 11 } & $\mathrm{p}=0,681$ & $\mathrm{p}=0,637$ & $\mathrm{p}=0,318$ & $\mathrm{p}=0,564$ & $\mathrm{p}=0,537$ & $\mathrm{p}=0,026$ & $\mathrm{p}=0,019$ & $\mathrm{p}=0,874$ & $\mathrm{p}=0,673$ & $\mathrm{p}=0,069$ \\
\hline \multirow{2}{*}{$\mathrm{G} 2$} & 0,100764 & $-0,164045$ & $-0,053114$ & 0,136205 & 0,069552 & $-0,147257$ & $-0,229972$ & 0,416146 & 0,065242 & 0,223049 \\
\cline { 2 - 11 } & $\mathrm{p}=0,583$ & $\mathrm{p}=0,370$ & $\mathrm{p}=0,773$ & $\mathrm{p}=0,457$ & $\mathrm{p}=0,705$ & $\mathrm{p}=0,421$ & $\mathrm{p}=0,205$ & $\mathrm{p}=0,018$ & $\mathrm{p}=0,723$ & $\mathrm{p}=0,220$ \\
\hline \multirow{2}{*}{$\mathrm{G} 3$} & $-0,604412$ & $-0,083830$ & $-0,592141$ & 0,041485 & 0,000000 & $-0,100141$ & $-0,243812$ & 0,036632 & 0,110755 & $-0,074186$ \\
\cline { 2 - 11 } & $\mathrm{p}=0,005$ & $\mathrm{p}=0,725$ & $\mathrm{p}=0,006$ & $\mathrm{p}=0,862$ & $\mathrm{p}=10,00$ & $\mathrm{p}=0,674$ & $\mathrm{p}=0,300$ & $\mathrm{p}=0,878$ & $\mathrm{p}=0,642$ & $\mathrm{p}=0,756$ \\
\hline \multirow{2}{*}{$\mathrm{G} 4$} & 0,275594 & $-0,118109$ & 0,305569 & 0,237033 & 0,076547 & 0,138821 & 0,354553 & 0,364593 & 0,143501 & 0,379989 \\
\cline { 2 - 11 } & $\mathrm{p}=0,182$ & $\mathrm{p}=0,574$ & $\mathrm{p}=0,137$ & $\mathrm{p}=0,254$ & $\mathrm{p}=0,716$ & $\mathrm{p}=0,508$ & $\mathrm{p}=0,082$ & $\mathrm{p}=0,073$ & $\mathrm{p}=0,494$ & $\mathrm{p}=0,061$ \\
\hline
\end{tabular}

Legenda: soma das pontuações dadas aos três itens que se usaram para cada competência e o valor do desempenho ponderado pela importância. Para os grupos 1,2 e 3 usou-se uma significância de 5\% e para G4 de $10 \%$.

Fonte: Dados da pesquisa (2013)

Para o grupo 1 as duas competências empreendedoras mais relacionadas com o desempenho são a busca de informações (BDI) e o estabelecimento de metas (EDM). Para o grupo 2 o planejamento e monitoramento sistemáticos (PMS) é quem se associa com o desempenho.

Em relação com o grupo 3 os sinais negativos indicam que quando diminuem os valores de $\mathrm{BOI} e$ EQE os valores do desempenho aumentam. Com relação à busca de oportunidades e iniciativas (BOI) cabe assinalar que nesse grupo nenhuma empresa obteve uma soma maior ou igual a 12 então é importante considerar que existe relação, mas não necessariamente seu sentido.

Já para a exigência de qualidade e eficiência (EQE) sim houve mais de $60 \%$ dos valores maiores do que doze, indicando a presença dessa competência. Entretanto se os seus valores se correlacionam com a importância e com a satisfação que os respondentes assinalaram se percebe que EQE só têm um coeficiente significativo e negativo para a satisfação. Ou seja, os respondentes que estão com valores altos para essa competência pontuam com notas baixas à satisfação com o desempenho, pois ao se exigirem na qualidade e eficiência não vem ao desempenho acorde com seu esforço.

Finalizando, o G4 não tem nenhuma competência relacionada com 95\% de confiança ao desempenho, contudo duas das competências do conjunto planejamento, EDM e PMS, mais a independência e autoconfiança (IAC) se relacionam positivamente com o desempenho se a significância utilizada for de 10\% (Tabela 5). 


\section{CONSIDERAÇÕES FINAIS}

O objetivo principal do trabalho foi avaliar se as competências empreendedoras que os proprietários de empresas prestadoras de serviços contábeis manifestam podiam ser relacionadas com o desempenho que eles percebiam de seus negócios. E, se constatada essa associação, procurar identificar quais as competências que se relacionavam com os diversos indicadores de desempenho usados. A impossibilidade de trabalhar as competências segundo ao conjunto ao que pertencia, isto é ao de realizações, de planejamento ou de poder, devido à falta de correlações entre elas, como mostrado na Tabela 1, obrigou a utilizar outras estratégias de análise.

A utilização de um valor mínimo como indicativo de que a competência estava presente no respondente foi empregada por Lenzi (2008), sendo o mesmo 13. Neste estudo optou-se por usar um valor menos restritivo, igual ou maior que 12. Essas novas informações permitiu segmentar a amostra em quatro grupos homogêneos e a partir procurar responder a questão de pesquisa. Podese então confirmar que os grupos se relacionavam de modo diferente com o desempenho e como eles se caracterizavam por ter números diferentes das dez competências consideradas (Tabela 3), houve motivo válido para buscar saber quais as competências que se correlacionavam com o desempenho segundo o grupo em que os respondentes se encaixavam.

Os resultados exibidos na Tabela 5 dão um indicativo de quais são as competências mais importantes a promover quando se busca melhorar o desempenho. Das cinco que compõem o conjunto de realizações, isto é busca de oportunidades e iniciativas (BOI); correr riscos calculados (CRC); exigência de qualidade e eficiência (EQE); persistência (PER); e, comprometimento (COM), só duas, BOI e EQE, aparecem com significância. Quanto ao conjunto planejamento as três competências que o formam, busca de informação (BDI), estabelecimento de metas (EDM), e planejamento e monitoramento sistemáticos (PMS), exibem relações significativas com o desempenho. Finalmente, das duas que pertencem ao conjunto poder, persuasão e rede de contatos (PRC) e à independência e autoconfiança (IAC), só IAC alcança significância ao $10 \%$.

Algumas limitações com os dados impossibilitaram usar métodos mais robustos nas análises estatísticas, entretanto foi possível evidenciar a relação e assim responder à hipótese de investigação formulada como uma pergunta. A prossecução dos estudos incluindo os funcionários das empresas prestadoras de serviços contábeis, não apenas os proprietários podem trazer novas contribuições, como avaliar o grau de intraempreendedorismo que exista e o auxílio deste para o desempenho.

\section{REFERÊNCIAS}

ANDRETTI, A. P. Ambiente organizacional, comportamento estratégico e desempenho Empresarial: estudo do setor hoteleiro de Macaé/ RJ. 2008. 128 f. Dissertação (Mestrado em Administração). Universidade do Vale do Itajaí, Biguaçu, Santa Catariana, 2008.

ANTONELLO, C. S. A. Metamorfose da aprendizagem organizacional: uma revisão crítica. In: RUAS, R. L.; ANTONELLO, C. S.; BOFF, L. H. e colaboradores. Os novos horizontes da gestão: Aprendizagem organizacional e competências. Porto Alegre: Bookman, 2005, p. 12-33.

CHAKRAVARTHY, B.S. Measuring strategic performance. Strategic management journal, v.7, n.5, p.437-447. 1996.

COOLEY, L. Entrepreneurship training and the strengthening of entrepreneurial performance. Final Report. Contract. Washington: USAID, 1990.

COOLEY, L. Seminário para Fundadores de Empresa. Manual del Capacitador. Washington: MSI, 1991.

CUNNINGHAM, J. B.; LISCHERON, J. C. Defining entrepreneurship. Journal of Small Business Management, v. 29, n. 1, p. 45-67, 1991.

DORNELAS, J. C. A. Empreendedorismo corporativo: como ser empreendedor, inovar e se diferenciar em organizações estabelecidas. 2. ed. Rio de Janeiro: Elsevier, 2003.

DRUCKER, P. Inovação e espírito empreendedor. São Paulo: Pioneira, 1987.

DUTRA, J. S. Competências: conceitos e instrumentos para a gestão de pessoas na empresa moderna. São Paulo: Atlas, 2004.

FILION, L. J. Empreendedorismo: empreendedores e proprietários de pequenos negócios.

Revista de Administração da USP, São Paulo, v. 34, n.2, 5-28, 1999.

GIMENEZ, F. A. P.; INÁCIO JÚNIOR, E. Investigando o potencial empreendedor e liderança criativa. In: ENCONTRO NACIONAL DA ASSOCIAÇÃO NACIONAL DOS CURSOS DE PÓSGRADUAÇÃO EM ADMINISTRAÇÃO, 26., 2002, Salvador. Anais... Salvador: Enanpad, 2002.

GULINI, P. L., ROSSETTO, C. R. Comportamento estratégico e ambiente organizacional: um estudo de caso no setor de provedores de internet de Santa Catarina. IV Congresso de Administração - Gestão Estratégica nas Organizações, v. 4, 2005, Alfenas. Anais...Alfenas: UNIFENAS, 2005.

GUPTA, A.; GOVINDARAJAN, V. Business unit 
strategy, managerial characteristics, and business unit effectiveness at strategy implementation. Academy of Management Journal, v. 27, n. 1, p. 2541, 1984

HISRICH, R. D.; PETERS, M. P.; SHEPHERD, D. A. Empreendedorismo. 7. ed. Porto Alegre: Bookman, 2009.

KENT, C.A.; SEXTON, D.L.; VESPER, K.H. (eds.). Encyclopedia of entrepreneurship. Englewood Cliffs: Prentice-Hall, 1982.

LE BOTERF, G. Desenvolvendo a competência dos profissionais. 3. ed. Revista e ampliada. Tradução Patrícia Chittoni Ramos Reuillard. Consultoria, supervisão e revisão técnica Claudia Bitencourt. Porto Alegre: ArtMed, 2003.

LENZI, F. C. Os empreendedores corporativos nas empresas de grande porte: um estudo da associação entre tipos psicológicos e competências empreendedoras. 2008. Tese (Doutorado em Administração) - Faculdade de Economia, Administração e Contabilidade da Universidade de São Paulo FEA/USP. 2008.

LENZI, F. C. et al. Talentos inovadores na empresa. Curitiba: Ibpex, 2011.

MAN, T. W. Y.; LAU, T. Entrepreneurial competencies of SME owner/managers in the Hong

Kong services sector: A qualitative analysis. Journal of Enterprising Culture, v. 8, n. 3, p. 235-254, 2000.

MAMEDE, M. I. de B.; MOREIRA, M. Z. Perfil de competências empreendedoras dos investidores Portugueses e Brasileiros: Um estudo comparativo na rede hoteleira do Ceará. In: EnANPAD: 2005. Anais...Brasília/DF.

MARINS, L. M.; ZAWISLAK, P. A. O desempenho inovativo de sete firmas brasileiras à luz de um conjunto de novos indicadores de inovação. In: Encontro Anual da Associação de Pós-Graduação e Pesquisa em Administração, Rio de janeiro. Anais do XXXIV EnANPAD, Rio de Janeiro/RJ, 2010.

McCLELLAND, D. C. Entrepreneurship and achievement motivation: approaches to the science of sócio-economic development. In: LEYGEL, P (org.). Paris: UNESCO, 1971.

MELLO, S .C. B.; LEÃO, A. L. M. S.; PAIVA, F. G. Competências empreendedoras de dirigentes de empresas brasileiras de médio e grande porte que atuam em serviços da nova economia. Revista de Administração Contemporânea, Curitiba: Vol. 10 nr. 4, 2006.

MITCHELMORE, S.: ROWLEY, J. Entrepreneurial competencies: a literature review and development agenda. International Journal of Entrepreneurial
Behaviour \& Research, vol.16, n. 2, p. 92-111, 2010.

MORALES, S. A. Relação entre competencias e tipos psicológicos junguianos nos empreendedores. 2004. Tese (Doutorado em Engenharia de Produção) Centro Tecnológico, Universidade Federal de Santa Catarina, Florianópolis, 2004.

NASSIF, V. M. J.; ANDREASSI, T.; SIMÕES, F. Competências empreendedoras: há diferenças entre empreendedores e intraempreendedores? Revista de Administração e Inovação, São Paulo, v. 8, n. 3, p.33-54, jul/set. 2011.

OLSON, E. M., SLATER, S. F.; HULT, G. T. M. The Performance implications of fit among busines strategic, marketing organization structure, and strategic behavior. Journal of Marketing, v. 69, n. 3, p. 49-65, 2005.

PELHAM, A. M., WILSON, D. T. A longitudinal study of the impact of market structure, firm structure, strategy, and market orientation culture on dimensions of small- firm performance. Journal of academy of marketing science, v. 24, n.1, p. 27-43, 1996.

PERIN, M. G.; SAMPAIO, C. H. Performance empresarial: uma comparação entre indicadores subjetivos e objetivos. In ENCONTRO ANUAL DAANPAD, 23., 1999, Foz do Iguaçu. Anais... Foz do Iguaçu: ANPAD, 1999.

ROCHA, A. C. B. Configuração de um sistema de avaliação de desempenho alicerçado no Balanced Scorecard para uma indústria de confecções de porte médio. 2002. Dissertação (Mestrado em Engenharia de Produção) - Engenharia de Produção, Universidade Federal de Santa Catarina, Florianópolis, 2002.

ROSA, S. B.; LAPOLLI, E. M. Santa Catarina: um estado que é uma vitrine de talentos. In: LAPOLLI, E. M,; FRANZANI, A. M. B; SOUZA, V. A B. (Orgs). Vitrine de talentos: notáveis empreendedores em Santa Catarina. Florianópolis: Pandion, 2010.

SCHMITZ, A. L. F. Competências empreendedoras: os desafios dos gestores de instituições de ensino superior como agentes de mudanças. Tese (Doutorado em Engenharia e Gestão do Conhecimento) - Centro Tecnológico, Universidade Federal de Santa Catarina, Florianópolis, 2012.

SCHUMPETER, J. A. The theory of economic development. Oxford University Press, Oxford, 1978

SIMONS, R. Performance measurement \& control systens for implementing strategy. New Jersey: Prentice-Hall, 2000.

SMITH, A. A riqueza das nações. São Paulo: Nova 
Cultural, 1985.

SNELL, R.; LAU, A. Exploring local competences salient for expanding small business. Journal of Management Development, v. 13, n.4, p. 4-15, 1994.

SPENCER JR., L. M.; SPENCER, S. M. Competence at work: models for superior performance. New York: John Wiley and Sons, 1993.

WANG, C.K., ANG, B.L. Determinants of venture performance in Singapore. Journal of small business management, v. 42, n. 4, p. 347-363, 2004.

WEBER, M. The theory of social and economic organization. Contributors: A. M. Henderson Transltr, Talcott Parsons - editor, Max Weber author. Publisher: Oxford University Press. Place of Publication: New York. Publication Year: 1947

ZARIFIAN, P. Objetivo competência: por uma nova lógica. São Paulo: Atlas, 2001. 